ARTIGO ORIGINAL

\title{
Efeitos a médio prazo da exploração seletiva no crescimento, mortalidade e recrutamento de Manilkara huberi (Ducke) A. Chev. em uma floresta amazônica
}

\author{
Mid-term effects of selective logging on the growth, mortality, and \\ recruitment of Manilkara huberi (Ducke) A. Chev. in an Amazonian \\ rainforest
}

\author{
Luiz Fernandes Silva Dionisio ${ }^{1}$ (1) \\ ${ }^{1}$ Universidade do Estado do Pará - UEPA, Belém, PA, Brasil
}

\begin{abstract}
Como citar: Dionisio, L. F. S. (2020). Efeitos a médio prazo da exploração seletiva no crescimento, mortalidade e recrutamento de Manilkara huberi (Ducke) A. Chev. em uma floresta amazônica. Scientia Forestalis, 48(125), e3154. https://doi.org/10.18671/scifor.v48n125.21
\end{abstract}

\section{Resumo}

A exploração seletiva causa distúrbios em florestas tropicais e afeta a dinâmica da floresta. Neste estudo, foi avaliado o crescimento, recrutamento e mortalidade de Manilkara huberi $\geq 45 \mathrm{~cm}$ DAP em diferentes florestas exploradas ao longo de 13 anos (2002 a 2015) na Amazônia Oriental. Os dados foram coletados em uma área controle não explorada e em quatro Unidades de Trabalho de 100 ha, divididas em 20 parcelas de 5 ha (total de 100 parcelas em 500 ha amostrados) e inventariadas a 100\% um ano antes da colheita e novamente em 2015. A maior taxa de mortalidade ocorreu aos cinco $(9,6 \%)$ e sete $\left(7,2 \%\right.$ ano $\left.^{-1}\right)$ anos após a colheita, com redução a partir dos onze anos $\left(4,2 \%\right.$ ano $\left.^{-1}\right)$, período em que não apresentou diferença significativa para a área controle $\left(1,9 \%\right.$ ano $\left.^{-1}\right)$. A taxa de recrutamento aumentou significativamente $\left(11,3 \%\right.$ ano $\left.^{-1}\right)$ aos sete anos e a partir de onze anos estabilizou. A exploração reduziu mais de $50 \%$ o número de indivíduos e área basal em todas as áreas após a colheita. Em áreas exploradas as maiores árvores ( $D A P \geq 75 \mathrm{~cm}$ ) são mais propensas a mortalidade. A área não explorada apresenta a maior taxa de crescimento. A taxa de crescimento de Manilkara huberi aumenta proporcionalmente ao tamanho da árvore na área não explorada.
\end{abstract}

Palavras-chave: Área basal; Colheita florestal, Densidade de indivíduos; Exploração de Impacto Reduzido; Floresta tropical

\begin{abstract}
Selective logging causes disturbances in tropical forests and affects forest dynamics. In this study, the growth, recruitment and mortality of Manilkara huberi $\geq 45 \mathrm{~cm}$ DBH in different forests logged along 13 years (2002-2015) in the Eastern Amazon. The data were collected in a control unlogged forest and in four 100-ha working units divided into 20 plots of 5 ha (total of 100 plots in 500 ha sampled) and inventoried at 100\% one year before harvesting and again in 2015. The highest mortality rate occurred at five (9.6\%) and seven (7.2\% year ${ }^{-1}$ ) years after harvest, with a reduction from the age of eleven $\left(4.2 \%\right.$ year $\left.^{-1}\right)$, when there was no significant difference for the control area $\left(1.9 \%\right.$ year $\left.^{-1}\right)$. The recruitment rate increased significantly $\left(11.3 \%\right.$ year $\left.{ }^{-1}\right)$ at seven years and from eleven years stabilized. Logging reduced the number of individuals and basal area by more than $50 \%$ in all areas after harvest. In explored areas the largest trees $(\mathrm{DBH} \geq 75 \mathrm{~cm}$ ) are more prone to mortality. The unexploited area has the highest rate of growth. The growth rate of Manilkara huberi increases proportionally to the size of the tree in the unexplored area.
\end{abstract}

Keywords: Basal area; Forest harvesting; Density of individuals; Reduced Impact Logging; Rainforest.

\author{
Fonte de financiamento: Nenhuma. \\ Conflito de interesse: Nada a declarar. \\ Autor correspondente: fernandesluiz03@gmail.com \\ Recebido: 6 outubro 2018 \\ Aceito: 2 maio 2019. \\ Editor: Francides Gomes da Silva Júnior.
}

(c) Este é um artigo publicado em acesso aberto (Open Access) sob a licença Creative Commons Attribution, que permite uso, distribuição e reprodução em qualquer meio, sem restrições desde que o trabalho original seja corretamente citado. 


\section{INTRODUÇÃO}

O corte seletivo de espécies arbóreas em florestas tropicais influencia diretamente na regeneração natural, crescimento, recrutamento e mortalidade de indivíduos que compõem as comunidades destas florestas (Schwartz et al., 2014; Arevalo et al., 2016; Darrigo et al., 2016; De Avila et al., 2017; Dionisio et al., 2017). O conhecimento sobre a dinâmica florestal é fundamental para seu manejo e conservação, permitindo regular os ciclos de corte e/ou intensidade de exploração conforme características da floresta (Dionisio et al., 2018a, 2018b).

Mesmo que algumas espécies comerciais apresentem altas densidades naturais, podem ser necessárias intervenções pós-colheita para aumentar o crescimento dessas espécies e garantir que a população da espécie manejada recuperem o volume colhido na primeira colheita. Portanto, o manejo das florestas tropicais de forma sustentável requer conhecimento sobre o comportamento do crescimento das árvores e sua resposta aos diferentes distúrbios (Abiyu et al., 2018), sejam eles naturais ou antrópicos.

Manilkara huberi, conhecida popularmente como maçaranduba é uma espécie nativa da floresta amazônica, pertencente à família Sapotaceae. Essa espécie foi classificada como espécie clímax por Azevedo et al. (2008b) e tolerante a sombra por Reis et al. (2013) e Castro \& Carvalho (2014). Esta espécie atinge cerca de $50 \mathrm{~m}$ de altura, com tronco ereto e cilíndrico com até $2 \mathrm{~m}$ de diâmetro (Ferraz et al., 2004). Devido à sua madeira muito resistente, tem sido um alvo preferido de colheita seletiva pela indústria madeireira (Azevedo et al., 2007).

Manilkara huberi é uma das espécies madeireira mais explorada na Amazônia, sendo comercializada no mercado nacional e internacional (Azevedo et al., 2007; Castro \& Carvalho, 2014). Dados registram a exploração da espécie para produtos florestais em $606,63 \mathrm{~m}^{3}$ para o estado de Roraima, $1.247,474 \mathrm{~m}^{3}$ para o estado do Amazonas, $87 \mathrm{~m}^{3}$ para o estado de Rondônia, e no Estado do Pará, no período de 2006 a 2015, foi de 3.614,81 m³ (Pará, 2015). De acordo com o Decreto Estadual $n^{\circ} 802$ de 20/02/2008 realizado pela Secretaria de Meio Ambiente e Sustentabilidade (SEMAS) do Governo do Pará a Manilkara huberi, encontra-se em estado de vulnerabilidade devido a sua alta exploração e baixa taxa de crescimento (Castro \& Carvalho, 2014).

A Manilkara huberi possui alta densidade específica $\left(1,03 \mathrm{~g} / \mathrm{cm}^{3}\right)$ (Rosa et al., 2014). Apresenta alta durabilidade natural e resistência ao ataque de fungos decompositores e cupins subterrâneos (Rosa et al., 2014; Castro \& Carvalho, 2014). Essas características fazem dessa espécie uma das mais utilizadas em construção civil e naval, cais para embarcações, torneados, chapas, instrumentos musicais, assoalhos, carrocerias para caminhões e outros (Rosa et al., 2014).

Para o manejo sustentável da espécie através da Exploração de Impacto Reduzido (EIR), o qual trata-se de um conjunto de técnicas que visa manter a estrutura e as funções da floresta colhida o mais semelhante possível de suas condições originais (Hirai et al., 2012), é importante avaliar a dinâmica de Manilkara huberi a longo prazo e como indivíduos dessa espécie respondem às perturbações pós-exploração para determinar se intervenções são necessárias para garantir rendimento suficiente de madeira para futuros ciclos de corte.

A maioria dos estudos em florestas tropicais sobre o efeito da EIR, tem o foco na regeneração natural (Hirai et al., 2012; Quadros et al., 2013; Asase et al., 2014; Arevalo et al., 2016; Darrigo et al., 2016; Rivett et al., 2016), sendo poucos os estudos específicos sobre os efeitos da EIR na mortalidade de árvores adultas remanescentes (Sist et al., 2003; Dionisio et al., 2018a). Portanto, há necessidade de informações mais detalhadas sobre como a EIR afeta árvores adultas remanescentes e como esses indivíduos respondem às perturbações pós-colheita.

A exploração seletiva de árvores grandes (DAP $\geq 50 \mathrm{~cm}$ ) através da EIR tem efeitos claros sobre a dinâmica da floresta (De Avila et al., 2017) com perdas de estoque. Esta perda compreende não somente o volume colhido e partes defeituosas das árvores derrubadas que não são aproveitadas e permanecem na floresta, mas também o volume das árvores que morrem durante e após a colheita florestal (Dionisio et al., 2017).

O conhecimento sobre o crescimento das espécies arbóreas, principalmente as de interesse econômico, em florestas manejadas é fundamental para o seu manejo adequado. Neste sentido, o presente estudo tem como objetivo avaliar os efeitos da colheita florestal sobre o recrutamento, 
crescimento e mortalidade da população remanescente de Manilkara huberi com DAP $\geq 45 \mathrm{~cm}$ em área submetida à EIR ao longo de 13 anos na fazenda Rio Capim, Pará.

\section{MATERIAL E MÉTODOS}

\section{Área de estudo}

A área de Manejo Florestal (AMF) da fazenda Rio Capim, pertencente à empresa CKBV

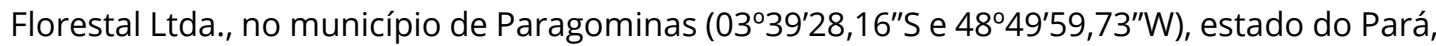
Brasil (Figura 1). A fazenda Rio Capim tem área total de 140.000 ha, onde 121.000 ha estão sob manejo florestal certificado pelo Forest Stewardship Council (FSC) desde 2001.


Figura 1. Área de estudo na fazenda Rio Capim, no município de Paragominas (C), Pará (B), Brasil (A). 20 parcelas de $50 \mathrm{~m}$ de largura por $1000 \mathrm{~m}$ de comprimento em cada unidade de trabalho (D) foram utilizadas para medir árvores comerciais $\geq 45 \mathrm{~cm}$ DAP em uma densa floresta ombrófila 13 anos (2002-2015) após a extração de impacto reduzido.

O ecossistema florestal característico da região é do tipo Floresta Ombrófila Densa (Instituto Brasileiro de Geografia e Estatística, 2012). De acordo com a classificação de Köppen, o clima da região é do tipo "Awi", isto é, tropical chuvoso, com precipitação pluviométrica média anual de $1.800 \mathrm{~mm}$, temperatura média anual de $26,3^{\circ} \mathrm{C}$ e umidade relativa do ar de $81 \%$ (Alvares et al., 2013). A altitude da região é de $20 \mathrm{~m}$ em relevo plano a levemente ondulado (Instituto Brasileiro de Geografia e Estatística, 2004; Sist \& Ferreira, 2007). Latossolos Amarelos, Argissolos Amarelos, Plintossolos, Gleissolos e Neossolos são os principais tipos de solos da região (Rodrigues et al., 2003).

Foram colhidas 49 espécies comerciais em 2002 e somente essas foram monitoradas ao longo de treze anos (2002 a 2015). Para esse estudo foi escolhido à espécie Manilkara huberi (Ducke) A. Chev., Standl., por ser uma das espécies com maior volume colhido (Dionisio et al., 
2018a). A densidade (ind.ha-1) média pré e pós-colheita de árvores de Manilkara huberi (árvores $\geq 45 \mathrm{~cm}$ DAP), para cada área manejada é apresentada na Tabela 1.

\section{Delineamento experimental}

Foi realizado um inventário florestal a 100\% em todas as Unidades de Trabalho (UTs) pré e pós-colheita. Os dados foram coletados em cinco Unidades de Trabalho (UTs) que fazem parte de cinco Unidades de Produção Anual (UPA) (uma UT por UPA). Quatro UPAs/UTs foram exploradas em diferentes anos (2002; 2004; 2008; e 2010), e um UPA/UT nunca explorada e monitorado desde 2006 foi usado como controle (Tabela 1). Cada área representa um ano de colheita, formando assim uma cronossequência de treze anos de monitoramento. As cinco áreas amostradas (quatro áreas exploradas e uma área controle) possuem as mesmas características edafoclimáticas descritas acima. As distâncias mínima e máxima em linha reta entre cada UT são 5 km e 24 km, respectivamente.

Tabela 1. Unidades de Produção Anual (UPAs) e Unidades de Trabalho (UTs) inventariadas entre 2002 e 2010 e remedidas em 2015, na fazenda Rio Capim, PA, Brasil.

\begin{tabular}{|c|c|c|c|c|c|c|c|}
\hline $\begin{array}{c}\text { Ano de } \\
\text { medição/ } \\
\text { remedição }\end{array}$ & $\begin{array}{l}\text { Ano pós } \\
\text { colheita }\end{array}$ & UPA/UT & $\begin{array}{l}\text { Volume } \\
\text { médio } \\
\text { colhido } \pm \mathrm{DP} \\
\left(\mathrm{m}^{3} \mathrm{ha}^{-1}\right)\end{array}$ & $\begin{array}{l}\text { Densidade } \\
\left.\text { (ind.ha }^{-1}\right)^{a}\end{array}$ & $\begin{array}{l}\text { Densidade } \\
\left.\text { (ind.ha }^{-1}\right)^{b}\end{array}$ & $\begin{array}{l}\text { Densidade } \\
(\text { ind.ha-1) }\end{array}$ & $\begin{array}{c}\text { Densidade } \\
\text { de recrutas } \\
(\text { ind.ha-1)c }\end{array}$ \\
\hline $2006-215$ & Controle & $8 / 8$ & 0,00 & 1,76 & - & 1,46 & 0,09 \\
\hline $2010-2015$ & 5 & $13 / 40$ & $27,96 \pm 2,10$ & 3,46 & 1,79 & 1,09 & 0,08 \\
\hline $2008-2015$ & 7 & $10 / 18$ & $29,14 \pm 1,94$ & 1,30 & 0,64 & 0,42 & 0,25 \\
\hline 2004-2015 & 11 & $7 / 14$ & $28,94 \pm 1,75$ & 1,60 & 0,63 & 0,37 & 0,11 \\
\hline 2002-2015 & 13 & $4 / 4$ & $26,43 \pm 2,53$ & 3,75 & 1,64 & 1,04 & 0,20 \\
\hline
\end{tabular}

*Para a área controle "a" e "c" representam os inventários de 2006 e 2015, respectivamente). aPré-exploração bPós-exploração (1 ano pós-colheita) 'Inventário de 2015

Em cada UT foram monitoradas 20 parcelas de $50 \mathrm{~m} \times 1000 \mathrm{~m}$, totalizando 100 parcelas de 5 ha cada, onde foram inventariadas as árvores com DAP $\geq 45 \mathrm{~cm}$. As medições nas árvores inventariadas ocorreram um ano antes da colheita florestal e, novamente, em 2015, em cada uma das quatro áreas exploradas. Na área de controle, as árvores inventariadas foram medidas em 2006 e 2015. Além da remedição das árvores remanescentes, foram inventariados todos os indivíduos recrutados da espécie Manilkara huberi com DAP $\geq 45$ no período entre medições de cada área explorada e da área controle.

\section{Análise de dados}

Foram determinadas a densidade de indivíduos e área basal (pré-colheita e pós-colheita), taxas de crescimento $(\mathrm{cm}$ ano-1) e mortalidade por classes de diâmetro e recrutamento da espécie Manilkara huberi com DAP $\geq 45$ em todos os anos de colheita amostrados. Em todas as áreas houve apenas uma colheita de madeira e realizado monitoramento (pré e pós-colheita e novamente em 2015 (Tabela 1).

Para uma comparação do balanço mortalidade-recrutamento, foi calculada a mortalidade para cada área explorada e para a área controle. Desta forma, foram calculadas as taxas anualizadas de mortalidade e recrutamento dos indivíduos remanescentes com DAP $\geq 45$ após a colheita no período de 13 anos utilizando as Equações 1 e 2, respectivamente: 


$$
\begin{aligned}
& \mathrm{m}=1-\left(\mathrm{N}_{\mathrm{t} 2} / \mathrm{N}_{\mathrm{t} 1}\right)^{(1 / \mathrm{t})} \\
& \mathrm{r}=\left(1-\left(1-\left(\mathrm{I} / \mathrm{N}_{\mathrm{t} 2}\right)^{(1 / \mathrm{t})}\right) \times 100\right.
\end{aligned}
$$

em que, $\mathrm{m}=$ taxa de mortalidade anual, $\mathrm{r}=$ taxa de recrutamento anual, $\mathrm{N}_{\mathrm{t} 1}=$ número de árvores vivas na amostragem inicial, $\mathrm{N}_{\mathrm{t} 2}=$ número de árvores que sobreviveram até a segunda amostragem, I = números de árvores recrutadas, e $\mathrm{t}$ = anos entre a primeira e a segunda amostragem (Sheil et al., 1995; Sheil \& May, 1996).

As taxas de mortalidade foram calculadas incluindo as árvores vivas na primeira medição com DAP $\geq 45$ e as árvores vivas remanescentes na remedição de 2015. O recrutamento foi calculado a partir da amostragem de novas árvores com diâmetro mínimo de $45 \mathrm{~cm}$ DAP na segunda medição.

As taxas de crescimento ( $\left.\mathrm{cm} \mathrm{ano}^{-1}\right)$ foram calculadas para cada ano de exploração e por classes de diâmetro. $\mathrm{O}$ diâmetro foi medido com fita diamétrica a 1,30 metro de altura do solo. As árvores foram marcas com tinta a 1,30 m para posteriores remedições. A taxa de crescimento foi calculada pela diferença entre as medidas de diâmetro das árvores nos períodos de 2002-2015, 2004-2015, 2006-2015, 2008-2015 e 2010-2015 (DAP final - DAP $\left._{\text {inicial }}\right) / T_{\text {(tempo). }}$.

Para a análise das taxas de crescimento por classe de diâmetro das árvores remanescentes foi feita a distribuição dos indivíduos em cinco classes com base em seus DAPs $(45-54,9 \mathrm{~cm} ; 55-64,9 \mathrm{~cm} ; 65-74,9 \mathrm{~cm} ; 75-84,9 \mathrm{~cm}$ e $\geq 85 \mathrm{~cm})$.

Para cada área (ano de exploração) foi realizada a distribuição diamétrica para a densidade de indivíduos pré e pós-colheita em oito classes de diâmetros $(45-54,9 \mathrm{~cm}$; $55-64,9 \mathrm{~cm} ; 65-74,9 \mathrm{~cm} ; 75-84,9 \mathrm{~cm} ; 85-94,9 \mathrm{~cm} ; 95-104,9 \mathrm{~cm} ; 105-114,9 \mathrm{~cm}$ e $\geq 115 \mathrm{~cm})$.

Analisou-se também a distribuição diamétrica do número de indivíduos em 2002 (pré e pós-exploração) e 2015 (13 anos após a exploração), tanto na área controle como nas áreas exploradas para efeito comparativo.

Para as análises estatísticas das taxas de mortalidade, recrutamento e crescimento, cada parcela de 5 ha foi considerada uma repetição. Os dados foram analisados utilizando as análises de medidas repetidas no tempo (ANOVA). Em caso de diferença significativa entre tratamentos, foi utilizado o teste post-hoc de Tukey para comparação das médias. Todos os parâmetros de dinâmica e análises estatísticas foram realizadas no programa $\mathrm{R}$ versão 3.6.1 (R CORE TEAM, 2019), ao nível de $p<0,05$ de significância.

\section{RESULTADOS E DISCUSSÕES}

\section{Taxa de mortalidade e recrutamento}

A taxa de mortalidade das árvores foi significativamente superior aos cinco anos $(9,6 \%$ $\left.a^{-1}, F_{4 ; 56}=26,32, p=0,001\right)$ e sete anos após a colheita $\left(7,2 \%\right.$ ano $\left.^{-1}, \mathrm{~F}_{4 ;} ; 6=26,32, p=0,001\right)$ (Figura 2). Aos onze $(4,2 \%)$ e treze $(3,5 \%)$ anos, as taxas de mortalidade não apresentaram diferenças significativas entre si e em relação à área controle, cuja taxa de mortalidade foi $1,99 \% \mathrm{ano}^{-1}$ em dez anos de monitoramento. A taxa de recrutamento foi significativamente superior aos sete anos após a exploração $\left(11,3 \%\right.$ ano-1 $\left., \mathrm{F}_{4 ; 21}=15,27, p=0,001\right) \mathrm{e}$, em todos os anos seguintes, as taxas de recrutamento não apresentaram diferenças significativas entre si e em relação à área controle (1,4\%) (Figura 2). 




Figura 2. Boxplot mostrando a taxa média de mortalidade (A) e recrutamento (B) de indivíduos da espécie Manilkara huberi com DAP $\geq 45 \mathrm{~cm}$ DAP em área de floresta ombrófila densa sob Exploração de Impacto Reduzido (EIR) em quatro Unidades de Produção Anual (UPAs) manejadas ao longo de 13 anos (2002-2015) e uma área de controle sem exploração na fazenda Rio Capim, PA, Brasil. A linha horizontal mais grossa representa a mediana, a caixa o intervalo interquartil e as linhas tracejadas os valores extremos, respectivamente. Letras indicam diferenças estatística significativas $(p=0,05)$ em ANOVA com o teste post-hoc de Tukey.

A taxa de recrutamento foi superior às taxas de mortalidade apenas aos sete anos pós-colheita apresentando uma tendência temporal de diminuição. Num estudo realizado por Dionisio et al. (2017) observou-se que os efeitos da exploração sobre as taxas de mortalidade permanecem entre sete e onze anos. As taxas de recrutamento de espécies comerciais com DAP $<15 \mathrm{~cm}$ aumentaram significativamente após a exploração madeireira na Floresta Nacional de Tapajós (De Avila et al., 2017). Tal crescimento observado pelos autores, está relacionado ao tamanho das árvores avaliadas (DAP $<15 \mathrm{~cm}$ ). No entanto, as taxas de recrutamento tiveram uma tendência temporal negativa em todas as áreas manejadas, indicando que o recrutamento diminuiu à medida que o dossel da floresta foi fechando. A EIR têm implicações diretas para a sustentabilidade das atividades madeireiras considerando a espécie Manilkara huberi, uma vez que, há um elevado número de árvore que morre nos primeiros anos após as intervenções de colheita e que o recrutamento diminui progressivamente ao longo do tempo.

Em florestas sob EIR, a manutenção da regeneração, crescimento e recrutamento de espécies arbóreas comerciais podem aumentar substancialmente as chances de conservação de uma floresta. No entanto, a eficácia da conservação dessas espécies arbóreas dependerá da aplicação de tratamentos silviculturais que promovam o estabelecimento e crescimento dessas espécies. Do ponto de vista silvicultural, esses tratamentos aumentam o crescimento e a produção de árvores em florestas tropicais (Azevedo et al., 2008a, De Avila et al., 2017) e favorecem o estabelecimento da regeneração natural e o crescimento de mudas que substituirão as perdas ocorridas durante a exploração (Silva et al., 1999). Portanto, o grande desafio do manejo de florestas tropicais é ajustar um modelo silvicultural que garanta aumento das taxas de crescimento e recrutamento de espécies arbóreas comerciais de crescimento lento como a $M$. huberi.

Os distúrbios florestais, incluindo os causados pela colheita florestal, que resultam em aberturas do dossel, podem ser usados como uma forma eficaz para aumentar a densidade de espécies arbóreas raras (baixa densidade) e/ou aquelas que apresentam baixa regeneração natural e crescimento lento. Schwartz \& Lopes (2015) propõem como silvicultura pós-colheita o enriquecimento de clareiras com espécies raras ou localmente ameaçadas. De acordo com esses autores, aumentar a densidade de indivíduos dessas espécies nas clareiras de exploração florestal pode funcionar como um refúgio artificial, mantendo sua diversidade genética. Isto é possível através da densificação assistida (aumento artificial do número de indivíduos por unidade de área de espécies arbóreas em seus próprios habitats naturais). Tal procedimento também pode garantir o terceiro ciclo de corte (25-35 anos) em florestas tropicais na Amazônia brasileira, uma vez que as espécies comerciais apresentam naturalmente baixas densidades e sofrem aumento na mortalidade pós-exploração (Dionisio et al., 2017). 


\section{Densidade e área basal de indivíduos}

A densidade de indivíduos pré e pós-colheita são apresentados na Figura 3A. A densidade de indivíduos diminuiu substancialmente em todas as áreas após a colheita. A colheita de árvores reduziu a densidade média de indivíduos de 3,0 $\pm 1,9$ para 1,6 \pm 0,8 ind. ha ${ }^{-1}$ imediatamente após a exploração e, cinco anos após a colheita esse número reduziu para $1,0 \pm 0,5$ ind. ha ${ }^{-1}$, ou seja, uma redução de $66,6 \%$ do número inicial de árvores comerciais de Manilkara huberi com DAP $\geq 45 \mathrm{~cm}$. Esse padrão se repetiu para todas as áreas explodas, mostrando que somente a colheita de árvores com DAP $\geq 50 \mathrm{~cm}$ é responsável por uma redução de mais $50 \%$ do número de indivíduos iniciais (Figura $3 \mathrm{~A}$ ). O mesmo resultado foi observado para a área basal (Figura 3 B). A área basal foi reduzida em mais de $50 \%$ pela colheita e ao longo dos treze anos de monitoramento a mortalidade das árvores remanescentes foi responsável por mais $14,3 \%$ da redução de área basal.

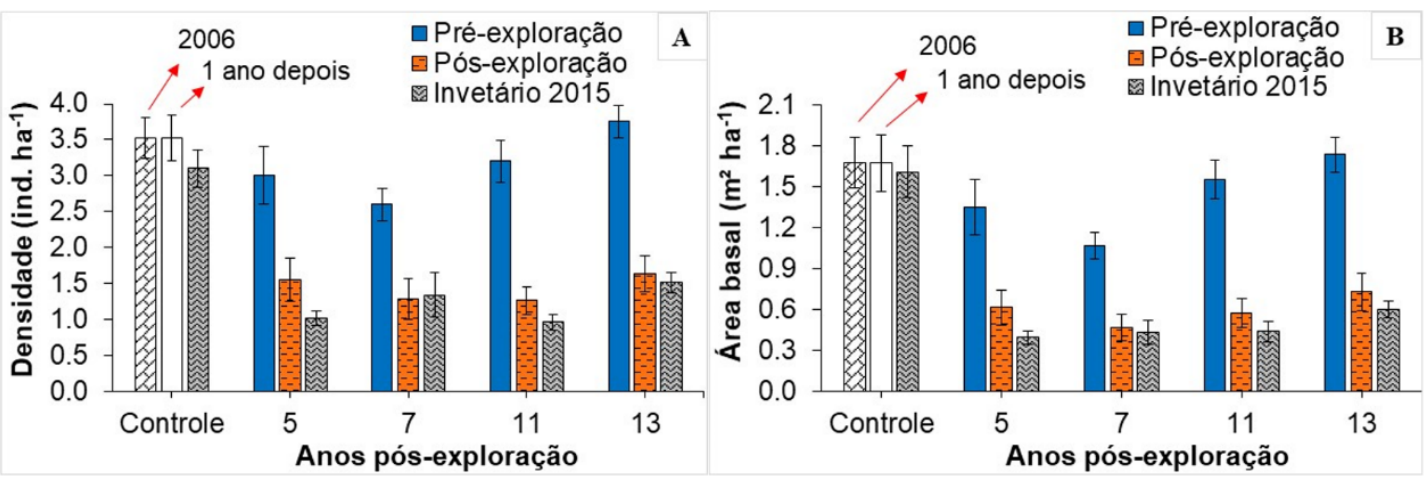

Figura 3. Média ( $\pm E P)$ da densidade de indivíduos (A) e área basal (B) de indivíduos da espécie Manilkara huberi com DAP $\geq 45 \mathrm{~cm}$ em área de floresta ombrófila densa sob Exploração de Impacto Reduzido (EIR) em quatro Unidades de Produção Anual (UPAs) manejadas ao longo de 13 anos (2002-2015) e uma área de controle sem exploração na fazenda Rio Capim, PA, Brasil. Pós-exploração (densidade de indivíduos e área basal imediatamente após a exploração).

No presente estudo a densidade de indivíduos e a área basal foram afetadas em todos os anos pós colheita. Essa redução já era esperada em todas as áreas devido a colheita de árvores (Figura 3A e 3B). Até os treze anos de monitoramento a espécie Manilkara huberi ainda não tinha recuperado a densidade de indivíduos e área basal pelo crescimento das árvores remanescentes e recrutamento de novos indivíduos. Visto que a espécie apresenta alta densidade da madeira, treze anos pós-colheita é um tempo relativamente curto para recuperação do estoque colhido dessa espécie (Figura 3A e 3B). A redução da densidade de indivíduos e da área basal ocorreu também devido a mortalidade de árvores remanescentes. Estudos mostram que grande parte das florestas tropicais primárias remanescentes vem sendo degradada pelo corte seletivo (Asner et al., 2005; International Tropical Timber Organization, 2012). Embora EIR possa causar menos impacto à floresta do que a exploração convencional, a exploração seletiva pode alterar as características do ambiente de forma direta, modificando a composição florística e a estrutura da comunidade, microclima no subbosque da floresta e microhabitats (Saunders et al., 1991; Fimbel et al., 2001; Schwartz et al., 2012; De Avila et al., 2017).

A mudança na estrutura de florestas manejadas é resultado da combinação da colheita de árvores com DAP $\geq 50 \mathrm{~cm}$, mortalidade após a exploração e baixo crescimento natural de espécies comerciais. Esses fatores têm implicações diretas para os futuros ciclos de corte, visto que algumas espécies colhidas poderão ser extintas.

\section{Distribuição diamétrica}

A colheita florestal não modificou a distribuição diamétrica da espécie ao longo dos 13 anos de estudo, no entanto, reduziu em mais de $50 \%$ o número de indivíduos nas classes de 55 a 84,9 cm (Figura 4B). Na área controle (Figura 4A) houve uma pequena redução no 
número de indivíduos por classe de diâmetro. Essa redução está associada as taxas de mortalidade natural observada na área controle. Ao longo deste período (2002-2015) houveram alguns anos muito secos na Amazônia, isto também pode explicar aumento de mortalidade das árvores remanescentes.
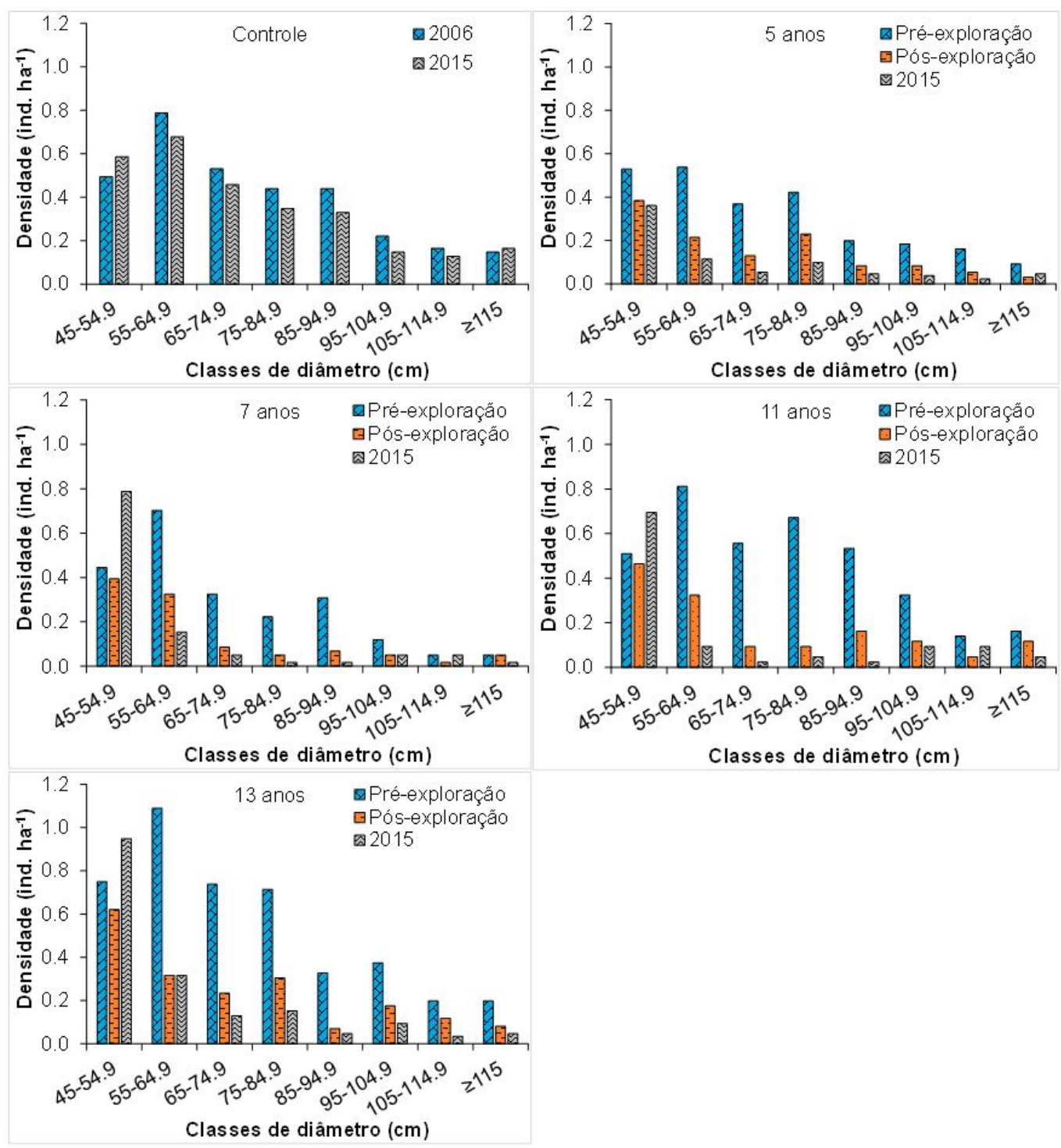

Figura 4. Distribuição diamétrica para indivíduos da espécie Manilkara huberi com DAP $\geq 45 \mathrm{~cm}$ em área de floresta ombrófila densa 13 anos após Exploração de Impacto Reduzido (EIR) em quatro Unidades de Produção Anual (UPAs) manejadas ao longo de 13 anos (2002-2015) e uma área de controle sem exploração na fazenda Rio Capim, PA, Brasil.

Aos treze anos pós-colheita mostrou uma distribuição diamétrica contínua e decrescente do tipo J-reverso. Aos 13 anos após a exploração, a espécie ainda mantém uma distribuição diamétrica decrescente, sendo que nas áreas de sete, onze e treze anos pós-colheita houve um aumento significativo no número de indivíduos na classe de 45-54,9 cm (Figura 4).

Reis et al. (2014) avaliando a distribuição diamétrica de Sapotaceae treze anos após a exploração de impacto reduzido no município de Moju, Estado do Pará, observaram que logo após a exploração, a espécie Manilkara huberi apresentou decréscimos em quatro das oito classes diamétricas de sua distribuição. Os autores afirmam que houve descontinuidade principalmente nas classes de 75 e $85 \mathrm{~cm}$, onde se concentrou a exploração, no entanto, a espécie manteve forma de J-invertido pós-exploração. 
Dionisio et al. (2018b) observaram que a exploração de impacto reduzido não afetou a estrutura da população de Duguetia spp, que no período 30 anos após a exploração, manteve sua distribuição natural decrescente, em forma de J-reverso, sendo que a espécie mostrou equilíbrio entre as taxas de mortalidade e recrutamento.

Em florestas naturais, a distribuição na forma de J-reverso é observada nas espécies tolerantes à sombra, caracterizando uma comunidade típica, autorregenerante, com maior número de indivíduos nas menores classes de diâmetro (Hess et al., 2010). As espécies com ausência de indivíduos nas classes de tamanho menores ou distribuição descontínua são consideradas helióflas (Jardim, 2015). As espécies cuja distribuição diamétrica tem forma intermediária entre esses extremos são oportunistas, podendo ser de grandes ou pequenas clareiras, conforme demandem mais ou menos luz para se estabelecerem (Jardim \& Soares, 2010).

Em nível de espécies, no entanto, a distribuição diamétrica pode diferir muito da forma J-invertido, de acordo com o comportamento ecofisiológico das espécies e as mudanças ocorridas ao longo do tempo (Carvalho \& Nascimento, 2009; Dalla Lana et al., 2013), principalmente após a exploração florestal, que, ao se colherem árvores em várias classes de diâmetro, com intensidade diferenciadas em determinadas classes, resulta em fortes alterações na distribuição diamétrica e, consequentemente, demanda-se muito tempo para a recuperação do estoque aproveitável das espécies colhidas (Reis et al., 2014).

\section{Taxa de mortalidade por classe de diâmetro}

A classe de diâmetro não teve efeito significativo sobre a taxa mortalidade, para indivíduos com DAP $\geq 45 \mathrm{~cm}$, na área controle $\left(\mathrm{F}_{4 ; 15}=0,695, p\right.$-valor $\left.=0,697\right)$. Nas áreas exploradas à medida que aumentou o diâmetro também aumentou a taxa de mortalidade das árvores remanescentes $\left(F_{4 ; 70}=9,202, p\right.$-valor $\left.=0,001\right)$ (Figura 5).

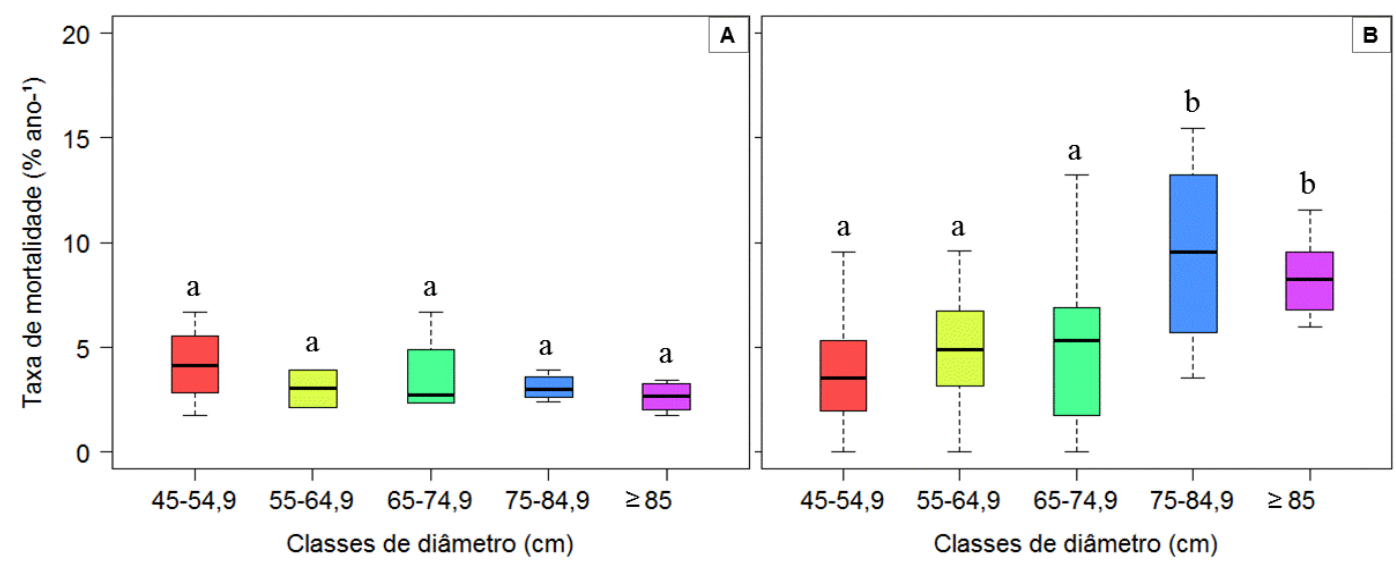

Figura 5. Boxplot mostrando a taxa média de mortalidade por classe de diâmetro para indivíduos da espécie Manilkara huberi com DAP $\geq 45 \mathrm{~cm}$ em área de floresta ombrófila densa 13 anos após

Exploração de Impacto Reduzido (EIR) em quatro Unidades de Produção Anual (UPAs) manejadas ao longo de 13 anos (2002-2015) e uma área de controle sem exploração na fazenda Rio Capim, PA, Brasil. (A) controle; e (B) área sob EIR. A linha horizontal mais grossa representa a mediana, a caixa o intervalo interquartil e as linhas tracejadas os valores extremos. Letras indicam diferenças estatística significativas $(p=0,05)$ em ANOVA com o teste post-hoc de Tukey.

Os resultados encontrados mostraram que, nas áreas sob EIR, as taxas de mortalidade foram influenciadas pelo tamanho das árvores para indivíduos com DAP $\geq 75 \mathrm{~cm}$. A mortalidade das árvores poderia diminuir com o aumento do DAP, pois árvores grandes são mais resistentes a tensões ou mudanças ambientais (Clark \& Clark, 1992; Blundell \& Peart, 2001). No entanto, acreditamos que abertura do dossel causado pela exploração deixa as maiores árvores mais suscetíveis aos ventos e por isso caem.

D'Oliveira \& Braz (2006) avaliando a mortalidade de árvores com DAP $\geq 5 \mathrm{~cm}$, em uma área de manejo florestal comunitário com volume colhido de $10 \mathrm{~m}^{3} \mathrm{ha}^{-1}$, encontraram uma 
taxa média de 3,2 ano ${ }^{-1}$, quatro anos após a exploração. Os autores observaram que não houve efeito do tamanho da árvore na taxa de mortalidade.

Alguns estudos têm mostrado que o tamanho da árvore é um dos atributos intrínsecos importantes que influencia fortemente a mortalidade (Wu et al., 2017; Dionisio et al., 2018a). No entanto, outros estudos observaram que não houve relação entre mortalidade e o tamanho da árvore para árvores muito grandes (Coomes \& Allen, 2007; Wang et al., 2012).

\section{Taxa de crescimento}

Foi observado maior taxa de crescimento na área controle em relação as áreas exploradas $\left(0,51 \mathrm{~cm}^{2} \mathrm{ano}^{-1}, \mathrm{~F}_{4 ; 429}=6,684, p=0,001\right)$, no entanto, as áreas exploradas não apresentaram diferenças significativas entre si para o crescimento de árvores com DAP $\geq 45 \mathrm{~cm}$ em relação aos diferentes anos pós-colheita (Figura 6).

A colheita de árvores pode ser considerada um tratamento silvicultural, pois remove parte das árvores comerciais abrindo clareiras na floresta, o que aumenta a incidência de luz no interior da floresta. O aumento na incidência de luz após a exploração madeireira influencia positivamente as taxas de crescimento de árvores remanescentes (Silva et al., 1995; Peña-Claros et al., 2008; Souza et al., 2015), mas o efeito permanece pouco tempo após as intervenções (Silva et al., 1995; Schwartz et al., 2012; Vatraz et al., 2016). No entanto, para $M$. huberi esse efeito não teve influência positiva no crescimento. Isso ocorreu porque árvores grandes (DAP $\geq 45 \mathrm{~cm}$ ) raramente ficam dentro de clareiras de exploração. Assim, o efeito da exploração é melhor observado quando se avalia indivíduos a partir do banco de plântulas (regeneração).

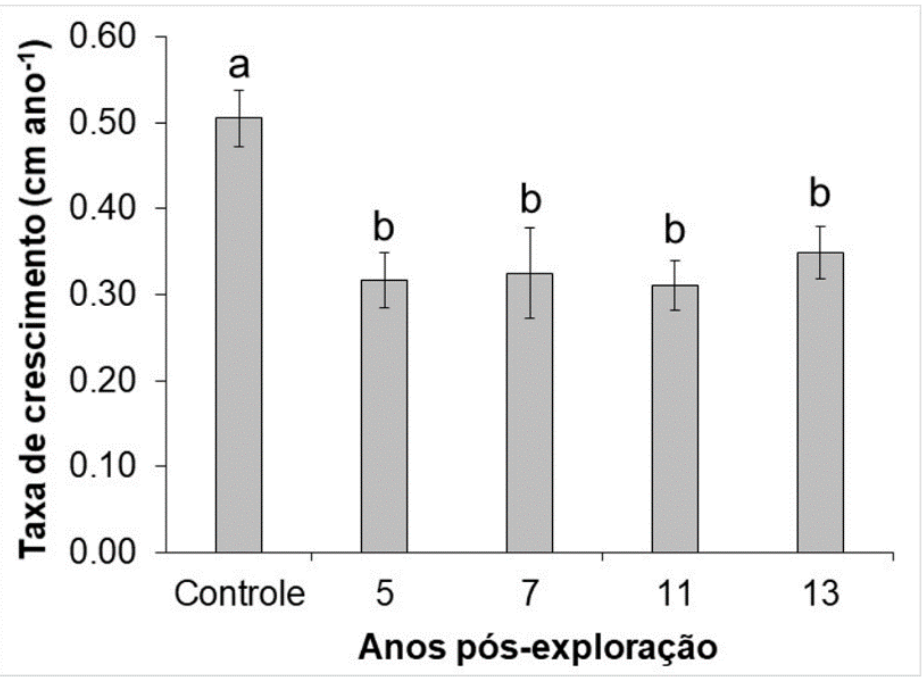

Figura 6. Média ( $\pm \mathrm{EP}$ ) para taxa de crescimento de indivíduos da espécie Manilkara huberi com DAP $\geq 45 \mathrm{~cm}$ em área de floresta ombrófila densa 13 anos após Exploração de Impacto Reduzido (EIR) em quatro Unidades de Produção Anual (UPAs) manejadas ao longo de 13 anos (2002-2015) e uma área de controle sem exploração na fazenda Rio Capim, PA, Brasil. Letras indicam diferenças significativas $(p=0,05)$ em ANOVA com o teste post-hoc de Tukey.

Souza et al. (2014) Manilkara huberi e Manilkara paraensis apresentaram crescimento positivo em de diâmetro, pós-exploração madeireira. Os autores afirmam que Manilkara huberi com maior grau de iluminação na copa apresentaram maior crescimento nos primeiros anos pós-colheita. Muitos estudos foram realizados para avaliar o efeito da aplicação de tratamentos silviculturais pós-colheita em diferentes espécies nativas da Amazônia. Esses estudos concluem que o tempo de monitoramento é fundamental para obter respostas concretas das espécies em relação aos tratamentos silviculturais (Vatraz et al., 2012; Souza et al., 2014; Taffarel et al., 2014a, 2014b; Martins et al., 2018). No entanto, todos os autores são categóricos ao afirmar que as espécies avaliadas se beneficiam de alguma forma à aplicação de tratamentos silviculturais mesmo que por um período curto (até 5 anos). 
As taxas de crescimento após a colheita de árvores encontradas nesse estudo não corroboram as observações em outras florestas tropicais manejadas (Peña-Claros et al., 2008, Souza et al., 2015; De Avila et al., 2017). Isso mostra a importância de tratamentos silviculturais pós-colheita para melhorar e manter as taxas de recrutamento e incremento M. huberi ao longo do tempo (Lopes et al., 2008; Schwartz \& Lopes, 2015; De Avila et al., 2017).

\section{Taxa de crescimento por classe de diâmetro}

$\mathrm{Na}$ área não explorada a taxa de crescimento aumentou de acordo com o aumento da classe de diâmetro. A classe $\geq 85 \mathrm{~cm}$ apresentou maior taxa de crescimento $\left(0,66 \mathrm{~cm}^{2} \mathrm{ano}^{-1}, \mathrm{~F}_{4}\right.$; $\left.{ }_{141}=3,305, p=0,05\right)$, diferindo significativamente das duas menores classes $(45-54,9$ e 55-64,9) (Figura 7A). As áreas exploradas não apresentaram diferença significativa para o crescimento em diâmetro $\left(\mathrm{F}_{4 ; 283}=1,988, p=0,0964\right)$ (Figura 7B).

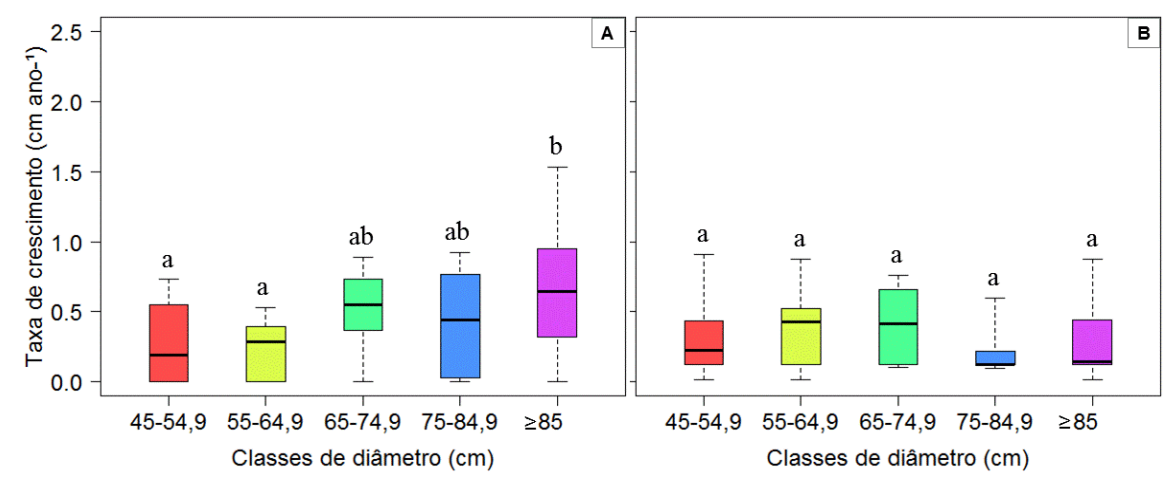

Figura 7. Boxplot mostrando taxa média de crescimento por classes de diâmetro de indivíduos da espécie Manilkara huberi com DAP $\geq 45 \mathrm{~cm}$ em área de floresta ombrófila densa sob Exploração de Impacto Reduzido (EIR) em quatro Unidades de Produção Anual (UPAs) manejadas ao longo de 13 anos (2002-2015) e uma área de controle sem exploração na fazenda Rio Capim, PA, Brasil. (A) controle; e (B) área sob EIR. A linha horizontal mais grossa representa a mediana, a caixa o intervalo interquartil e as linhas tracejadas os valores extremos. Letras indicam diferenças estatísticas significativas $(p=0,05)$ em ANOVA com o teste post-hoc de Tukey.

Carvalho et al. (2004), na Floresta Nacional de Tapajós, observaram maiores taxas de crescimento de diâmetro para classes maiores em relação a classes menores em uma área não explorada. No entanto, não foram encontradas diferenças no incremento de diâmetro entre classes de diâmetro maiores e menores em uma floresta explorada, possivelmente porque todas as classes de tamanho de árvore se tornaram mais expostos à incidência de luz após a exploração.

A maior taxa de crescimento observada na área não manejada (controle) (Figura 6) pode ser explicada quando observamos o crescimento por classes de diâmetro (Figura 7A). As maiores árvores são responsáveis pela maior taxa de crescimento da floresta. Assim, como não houve corte de árvores na área controle, a mesma apresentou as maiores taxas de crescimento em função dos maiores indivíduos presente na área.

\section{Implicações da EIR para o manejo florestal}

Apesar das grandes vantagens na conservação de serviços do ecossistema, a Exploração de Impacto reduzido (EIR) provoca significativos aumentos nas taxas de mortalidade pós-colheita (Bertault \& Sist, 1997; Dionisio et al., 2017, 2018b).

Operações de colheita florestal geram resíduos de madeira e impacto na floresta remanescente (Silva et al., 2018). A atividade de colheita florestal é responsável por 30\% de impactos negativos nas árvores remanescentes, sendo $7 \%$ de exploração, 3\% de troncos de árvores, $4 \%$ de árvores danificadas, 6,6\% de trilhas de arraste e 9,4\% de clareiras (Pinto et al., 2002). A grande preocupação entre os manejadores de florestas é o rendimento em volume de madeira das espécies colhidas, as quais podem não se recuperar entre a primeira e a 
segunda colheita. O crescimento do estoque comercial remanescente deve ser tal que o volume perdido durante a operação de colheita seja substituído dentro de um ciclo de corte. Esta perda compreende não somente o volume colhido e partes defeituosas das árvores derrubadas que não são aproveitadas e permanecem na floresta, mas também o volume das árvores que morrem durante e após a colheita florestal.

A escassez de regeneração natural de espécies comerciais em florestas tropicais exploradas (van Rheenen et al., 2004; Park et al., 2005; Schwartz et al., 2017a) são fatores que tem implicações diretas nos futuros ciclos de corte. Somando-se a isso, tem-se o volume retirado por colheita e o volume de madeira perdido devido ao aumento nas taxas de mortalidade pós-colheita. A junção desses fatores pode resultar em rendimentos mais baixos nos futuros ciclos de corte, inviabilizado a colheita florestal.

As práticas silviculturais pós-colheita para aumentar as taxas de crescimento das espécies arbóreas comerciais, o plantio de espécies de valor econômico (Schwartz et al., 2017b) e o aproveitamento do volume perdido por mortalidade tornam-se fundamentais para equilibrar as perdas de madeira em florestas tropicais devido às colheitas.

No atual sistema silvicultural policíclico aplicado em florestas nativas na Amazônia, algumas questões devem ser revisadas a fim de alcançar uma produção mais sustentável, principalmente no que tange a exploração madeireira concentrada em poucas espécies, diâmetro mínimo de corte (DMC) e ciclo de corte. O corte seletivo de algumas espécies de maior valor comercial visa atender a demanda do mercado madeireiro, no entanto a pressão exercida sobre um grupo restrito de espécies pode interferir negativamente na dinâmica e estrutura das florestas manejadas.

Espécies mais exploradas como Manilkara huberi deve ter um monitoramento constante para evitar que elas se tornem vulneráveis ou extintas localmente. A DMC deve ser aplicada especificamente para cada espécie, em vez de uma DMC geral para todas as espécies comerciais (ou seja, $\geq 50 \mathrm{~cm}$ na Amazônia brasileira). O atual ciclo de corte adotado na Amazônia brasileira (25 a 35 anos) pode não ser adequado para a recuperação de volume de muitas espécies, enquanto muitas outras espécies pioneiras e demandantes de luz são capazes de recuperar seus volumes em menos de 25 anos. Assim, nas colheitas subsequentes novas espécies comerciais e com potencial de comercialização são incluídas para corte (Reis et al., 2010; Hawthorne et al., 2012; Macpherson et al., 2012).

De acordo com as regulações ambientais referentes a manejo florestal no Brasil, especificamente do estado do Pará, a IN-5 de 2015 (Brasil, 2015) prevê que os manejadores florestais podem adotar medidas para regular o rendimento florestal. Essas medidas estabeleceriam um equilíbrio entre a intensidade da exploração florestal e o tempo necessário para recuperar o volume de madeira colhida, a fim de alcançar a produção florestal contínua. Assim, os manejadores florestais, baseados em estudos técnicos e científicos, podem sugerir mudanças no atual ciclo de corte (25-35 anos) e no diâmetro mínimo de corte ( $\geq 50 \mathrm{~cm}$ ) de acordo com o potencial de produção florestal.

O baixo crescimento natural de espécies comerciais em florestas tropicais manejadas e a colheita de árvores com DAP $\geq 50 \mathrm{~cm}$ são fatores que têm implicações diretas para os futuros ciclos de corte, visto que árvores com maior diâmetro são responsáveis por maior taxa de crescimento. Somando-se a isso, tem-se o volume retirado por colheita e o volume de madeira perdido devido a altas taxas de mortalidade pós-colheita (Dionisio et al., 2018a). A junção desses fatores pode resultar na inviabilidade da segunda colheita florestal (entre 25-35 anos na Amazônia brasileira) e em rendimentos mais baixos em futuros ciclos de corte.

Para equilibrar perdas em volume de madeira em florestas tropicais manejadas devido à exploração, práticas silviculturais pós-colheita devem ser adotadas para aumentar as taxas de crescimento e recrutamento das espécies arbóreas comerciais, assim como diminuir suas taxas de mortalidade. O enriquecimento de clareiras criadas pela exploração florestal com espécies de valor comercial e o aproveitamento do volume perdido por mortalidade tornamse fundamentais para o equilíbrio do volume explorado de madeira em florestas manejadas (Sabogal et al., 2009; Castro et al., 2013; Schwartz et al., 2017b). 


\section{CONCLUSÃO}

A EIR afeta significativamente as taxas de mortalidade de Manilkara huberi após a exploração, no entanto, essas taxas se estabilizam a partir de onze anos. As altas taxas de recrutamento aos sete anos após a colheita de árvores compensam parte do estoque perdido por mortalidade. Em áreas exploradas as maiores árvores (DAP $\geq 75 \mathrm{~cm}$ ) apresentaram maior taxa de mortalidade. A colheita seletiva reduziu em mais de $50 \%$ o número de indivíduos e área basal em todos áreas exploradas. Manilkara huberi apresenta menor taxa de crescimento em diâmetro na área manejada. A taxa de crescimento das árvores aumenta proporcionalmente ao tamanho da classe de diâmetro na área controle. Mesmo após a colheita, a espécie apresenta uma distribuição diamétrica em forma de "J" invertido, ou seja, comportamento padrão em florestas tropicais. É de grande importância seguir monitorando o crescimento e a sobrevivência da espécie pós-colheita, para determinar o tempo necessário de recuperação do estoque colhido, com vista ao seu manejo adequado e sua utilização sustentável, pois Manilkara huberi é uma das espécies comerciais mais abundantes e mais colhidas na Amazônia.

\section{AGRADECIMENTOS}

A presente pesquisa fez parte do projeto Diagflor (MP3 - 03.13.07.004.00), coordenado pela Embrapa Amazônia Oriental. Agradecemos a equipe do Diagflor e a CKBV Florestal Ltda. e sua equipe de campo. O autor agradece ao CNPq (142462 / 2015-2) pela concessão da bolsa de doutorado.

\section{REFERÊNCIAS BIBLIOGRÁFICAS}

Abiyu, A., Mokria, M., Gebrekirstos, A., \& Bräuning, A. (2018). Tree-ring record in Ethiopian church forests reveals successive generation differences in growth rates and disturbance events. Forest Ecology and Management, 409, 835-844. http://dx.doi.org/10.1016/j.foreco.2017.12.015.

Alvares, C. A., Stape, J. L., Sentelhas, P. C., Gonçalves, J. L. M., \& Sparovek, G. (2013). Köppen's climate classification map for Brazil. Meteorologische Zeitschrift (Berlin), 22(6), 711-728. http://dx.doi.org/10.1127/0941-2948/2013/0507.

Arevalo, B., Valladarez, J., Muschamp, S., Kay, E., Finkral, A., Roopsind, A., \& Putz, F. E. (2016). Effects of reduced-impact selective logging on palm regeneration in Belize. Forest Ecology and Management, 369, 155-160. http://dx.doi.org/10.1016/j.foreco.2016.03.040.

Asase, A., Asiatokor, B. K., \& Ofori-Frimpong, K. (2014). Effects of selective logging on tree diversity and some soil characteristics in a tropical forest in southwest Ghana. Journal of Forestry Research, 25(1), 171-176. http://dx.doi.org/10.1007/s11676-014-0443-4.

Asner, G. P., Knapp, D. E., Broadbent, E. N., Oliveira, P. J. C., Keller, M., \& Silva, J. N. (2005). Selective logging in the Brazilian Amazon. Science, 310(5747), 480-482. http://dx.doi.org/10.1126/science.1118051. PMid:16239474.

Azevedo, C. P., Sanquetta, C. R., Silva, J. N. M., \& Machado, S. A. (2008a). Efeito de diferentes níveis de exploração e de tratamentos silviculturais sobre a dinâmica da floresta remanescente. Floresta, 38(2), 277-293. http://dx.doi.org/10.5380/rf.v38i2.11622.

Azevedo, V. C. R., Kanashiro, M., Grattapaglia, D., \& Ciampi, A. Y. (2008b). Variabilidade no cpDNA em Manilkara huberi, espécie sob manejo sustentável na Amazônia brasileira. Pesquisa Agropecuária Brasileira, 43(7), 859-867. http://dx.doi.org/10.1590/S0100-204X2008000700010.

Azevedo, V. C., Kanashiro, M., Ciampi, A. Y., \& Grattapaglia, D. (2007). Genetic structure and mating system of Manilkara huberi (Ducke) A. Chev., a heavily logged Amazonian timber species. The Journal of Heredity, 98(7), 646-654. http://dx.doi.org/10.1093/jhered/esm074. PMid:17873149.

Bertault, J. G., \& Sist, P. (1997). An experimental comparison of different harvesting intensities with reduced-impact and conventional logging in East Kalimantan, Indonesia. Forest Ecology and Management, 94(1-3), 209-218. http://dx.doi.org/10.1016/S0378-1127(96)03974-6.

Blundell, A. G., \& Peart, D. R. (2001). Growth strategies of a shade-tolerant tropical tree: the interactive effects of canopy gaps and simulated herbivory. Journal of Ecology, 89(4), 608-615. http://dx.doi.org/10.1046/j.0022-0477.2001.00581.x.

Brasil. Secretaria de Estado de Meio Ambiente e Sustentabilidade - SEMAS. (2015, 10 de setembro). Instrução Normativa SEMA Nº 5, de 10 de setembro de 2015. Dispõe sobre procedimentos técnicos 
para elaboração, apresentação, execução e avaliação técnica de Plano de Manejo Florestal Sustentável - PMFS nas florestas nativas exploradas ou não e suas formas de sucessão no Estado do Pará, e dá outras providências. Diário Oficial [da] República Federativa do Brasil, Brasília.

Carvalho, F. A., \& Nascimento, M. T. (2009). Estrutura diamétrica da comunidade e das principais populações arbóreas de um remanescente de Floresta Atlântica Submontana (Silva Jardim-RJ , Brasil). Revista Árvore, 33(2), 327-337. http://dx.doi.org/10.1590/S0100-67622009000200014.

Carvalho, J. O. P., Silva, J. N. M., \& Lopes, J. D. C. A. (2004). Growth rate of a terra firme rain forest in Brazilian Amazonia over an eight-year period in response to logging. Acta Amazonica, 34(2), 209-217. http://dx.doi.org/10.1590/S0044-59672004000200009.

Castro, T. C., \& Carvalho, J. O. P. (2014). Dinâmica da população de Manilkara huberi (Ducke) A. Chev. durante 26 anos após a exploração florestal em uma área de terra firme na Amazônia brasileira. Ciência Florestal, 24(1), 161-169. http://dx.doi.org/10.5902/1980509813333.

Castro, T. C., Carvalho, J. O. P., \& Gomes, J. M. (2013). O tamanho da clareira não influencia no comportamento de mudas de Manilkara elata plantadas após a colheita da madeira. Revista de Ciências Agrárias (Belém), 56(2), 120-124. http://dx.doi.org/10.4322/rca.2013.019.

Clark, D. A., \& Clark, D. B. (1992). Life history diversity of canopy and emergent trees in a Neotropical rain forest. Ecological Monographs, 62(3), 315-344. http://dx.doi.org/10.2307/2937114.

Coomes, D. A., \& Allen, R. B. (2007). Mortality and tree-size distributions in natural mixed-age forests. Journal of Ecology, 95(1), 27-40. http://dx.doi.org/10.1111/j.1365-2745.2006.01179.x.

D'Oliveira, M. V. N., \& Braz, E. M. (2006). Estudo da dinâmica da floresta manejada no projeto de manejo florestal comunitário do PC Pedro Peixoto na Amazônia Ocidental. Acta Amazonica, 36(2), 177-182. http://dx.doi.org/10.1590/S0044-59672006000200007.

Dalla Lana, M., Brandão, C. F. L. S., Pellico Neto, S., Marangon, L. C., \& Retslaff, F. A. S. (2013). Distribuição diamétrica de Escheweilera ovata em um fragmento de Floresta Ombrófla Densa Igarassu, PE. Floresta, 43(1), 59-68. http://dx.doi.org/10.5380/rf.v43i1.25252.

Darrigo, M. R., Venticinque, E. M., \& Santos, F. A. M. (2016). Effects of reduced impact logging on the forest regeneration in the central Amazonia. Forest Ecology and Management, 360, 52-59. http://dx.doi.org/10.1016/j.foreco.2015.10.012.

De Avila, A. L., Schwartz, G., Ruschel, A. R., Lopes, J. C., Silva, J. N. M., Carvalho, J. O. P., \& Bauhus, J. (2017). Recruitment, growth and recovery of commercial tree species over 30 years following logging and thinning in a tropical rain forest. Forest Ecology and Management, 385, 225-235.

Dionisio, L. F. S., Schwartz, G., Lopes, J. C., \& Oliveira, F. A. (2018a). Growth, mortality, and recruitment of tree species in an Amazonian rainforest over 13 years of reduced impact logging. Forest Ecology and Management, 430, 150-156. http://dx.doi.org/10.1016/j.foreco.2018.08.024.

Dionisio, L. F. S., Carvalho, J. O. P., Schwartz, G., Leão, F. M., \& Castro, T. C. (2018b). Incremento, recrutamento e mortalidade pós-colheita de Duguetia spp. na Floresta Nacional do Tapajós, Pará. Scientia Forestalis, 46(119). http://dx.doi.org/10.18671/scifor.v46n119.05.

Dionisio, L. F. S., Schwartz, G., Mazzei, L., Lopes, J. C., Santos, G. G. A., \& Oliveira, F. A. (2017). Mortality of stocking commercial trees after reduced impact logging in eastern Amazonia. Forest Ecology and Management, 401, 1-7. http://dx.doi.org/10.1016/j.foreco.2017.06.060.

Ferraz, I. K., Leal-Filho, N., Imakawa, A. M., Varela, V. P., \& Pina-Rodrigues, F. C. M. (2004). Características básicas para um agrupamento ecológico preliminar de espécies madeireiras da floresta de terra firme da Amazônia Central. Acta Amazonica, 34(4), 621-633. http://dx.doi.org/10.1590/S004459672004000400014.

Fimbel, R. A., Grajal, A., \& Robinson, J. G. (2001). Logging-wildlife issues in the tropics: an overview. In R. Fimbel, A. Grajal, J. G. Robinson (Eds.), The cutting edge: conserving wildlife in logged tropical forests (pp. 7-10). New York: Columbia University Press. http://dx.doi.org/10.7312/fimb11454-004.

Hawthorne, W. D., Sheil, D., Agyeman, V. K., Abu Juam, M., \& Marshall, C. A. M. (2012). Logging scars in Ghanaian high forest: towards improved models for sustainable production. Forest Ecology and Management, 271, 27-36. http://dx.doi.org/10.1016/j.foreco.2012.01.036.

Hess, A. F., Calgarotto, A. R., Pinheiro, R., \& Wanginiak, T. C. R. (2010). Proposta de manejo de Araucaria angustifolia utilizando o quociente de Liocourt e análise de incremento, em propriedade rural no Município de Lages, SC. Pesquisa Florestal Brasileira, 30(64), 337-345. http://dx.doi.org/10.4336/2010.pfb.30.64.337.

Hirai, E. H., Carvalho, C. J. R., Silva, J. N. M., Carvalho, J. O. P., \& Queiroz, W. T. (2012). Efeitos da exploração de impacto reduzido sobre a regeneração natural em uma floresta densa de terra firme no município de Paragominas na Amazônia brasileira. Scientia Forestalis, 40(95), 306-315. 
Instituto Brasileiro de Geografia e Estatística - IBGE. (2004). Mapa de vegetação do Brasil. Rio de Janeiro: IBGE.

Instituto Brasileiro de Geografia e Estatística - IBGE. (2012). Manual técnico da vegetação brasileira (2. ed.). Rio de Janeiro: IBGE.

International Tropical Timber Organization - ITTO. (2012). Annual review and assessment of the world timber situation Yokohama: ITTO.

Jardim, F. C. S. (2015). Natural regeneration in tropical forests. Revista de Ciências Agrárias (Belém), 58(1), 105-113. http://dx.doi.org/10.4322/rca.1676.

Jardim, F. C. S., \& Soares, M. S. (2010). Comportamento de Sterculia pruriens (Aubl.) Schum. em floresta tropical manejada em Moju-PA. Acta Amazonica, 40(3), 535-542. http://dx.doi.org/10.1590/S004459672010000300012.

Lopes, J. C. A., Jennings, S. B., \& Matni, N. M. (2008). Planting mahogany in canopy gaps created by commercial harvesting. Forest Ecology and Management, 255(2), 300-307. http://dx.doi.org/10.1016/j.foreco.2007.09.051.

Macpherson, A. J., Carter, D. R., Schulze, M. D., Vidal, E., \& Lentini, M. W. (2012). The sustainability of timber production from Eastern Amazonian forests. Land Use Policy, 29(2), 339-350. http://dx.doi.org/10.1016/j.landusepol.2011.07.004.

Martins, W. B. R., Pinto, A. R. G., Costa, J. S., Carvalho, J. O. P., Castro, T. C., \& Ruschel, A. R. (2018), Dinâmica da população de Lecythis idatimon Aubl. no período de 30 anos em uma floresta de terra firme manejada na Amazônia brasileira. Scientia Forestalis, 46(120). http://dx.doi.org/10.18671/scifor.v46n120.03.

Pará. Secretaria de Estado de Meio Ambiente. (2015). Extração e movimentação de toras de madeira nativa (413 p.). Belém: Secretaria de Estado de Meio Ambiente.

Park, A., Justiniano, M. J., \& Fredericksen, T. S. (2005). Natural regeneration and environmental relationships of tree species in logging gaps in a Bolivian tropical forest. Forest Ecology and Management, 217(2-3), 147-157. http://dx.doi.org/10.1016/j.foreco.2005.05.056.

Peña-Claros, M., Fredericksen, T. S., Alarcón, A., Blate, G. M., Choque, U., Leaño, C., Licona, J. C., Mostacedo, B., Pariona, W., Villegas, Z., \& Putz, F. E. (2008). Beyond reduced-impact logging: silvicultural treatments to increase growth rates of tropical trees. Forest Ecology and Management, 256(7), 1458-1467. http://dx.doi.org/10.1016/j.foreco.2007.11.013.

Pinto, A. C. M., Souza, A. L., Souza, A. P., Machado, C. C., Minette, L. J., \& Vale, A. B. (2002). Análise de danos de colheita de madeira em Floresta Tropical Úmida sob regime de manejo florestal sustentado na Amazônia Ocidental. Revista Árvore, 26(4), 459-466. http://dx.doi.org/10.1590/S010067622002000400008 .

Quadros, L. C. L., Carvalho, J. O. P., Gomes, J. M., Taffarel, M., \& Silva, J. C. F. (2013). Sobrevivência e crescimento de mudas de regeneração natural de Astronium gracile Engl. em clareiras causadas por exploração florestal na Amazônia brasileira. Ciência Florestal, 23(3), 411-416. http://dx.doi.org/10.5902/1980509810552.

R CORE TEAM (2019). R: a language and environment for statistical computing. Vienna, Austria: $\mathrm{R}$ Foundation for Statistical Computing. www.r-project.org.

Reis, L. P., Ruschel, A. R., Coelho, A. A., Luz, A. S., \& Martins-Da-Silva, R. C. V. (2010). Avaliação do potencial madeireiro na Floresta Nacional do Tapajós após 28 anos da exploração florestal. Pesquisa Florestal Brasileira, 30(64), 265-281. http://dx.doi.org/10.4336/2010.pfb.30.64.265.

Reis, L. P., Ruschel, A. R., Silva, J. N. M., Reis, P. C. M., Carvalho, J. O. P., \& Soares, M. H. M. (2014). Dinâmica da distribuição diamétrica de algumas espécies de Sapotaceae após exploração florestal na Amazônia Oriental. Revista de Ciências Agrárias (Belém), 57(3), 234-243. http://dx.doi.org/10.4322/rca.ao1401.

Reis, L. P., Silva, J. N. M., Reis, P. C. M., Carvalho, J. O. P., Queiroz, W. T., \& Ruschel, A. R. (2013). Efeito da exploração de impacto reduzido em algumas espécies de Sapotaceae no leste da Amazônia. Floresta, 43(3), 395-406. http://dx.doi.org/10.5380/rf.v43i3.30808.

Rivett, S. L., Bicknell, J. E., \& Davies, Z. G. (2016). Effect of reduced-impact logging on seedling recruitment in a neotropical forest. Forest Ecology and Management, 367, 71-79. http://dx.doi.org/10.1016/j.foreco.2016.02.022.

Rodrigues, T. E., Silva, R. C., Silva, J. M. L., Oliveira Júnior, R. C., Gama, J. R. N. F., \& Valente, M. A. (2003). Caracterização e classificação dos solos do Município de Paragominas, Estado do Pará (Documentos, 162, pp. 51). Belém: Embrapa Amazônia Oriental. 
Rosa, R. A., França, L. C. A., Segundinho, P. G. A., Lube, V. M., \& Paes, J. B. (2014). Caracterização da madeira de Maçaranduba (Manilkara sp.) por métodos destrutivos e não destrutivos. Ciência da Madeira, 5(1), 68-78. http://dx.doi.org/10.12953/2177-6830.v05n01a07.

Sabogal, C., Pokorny, B., Silva, J. N. M., Carvalho, J. O. P., Zweede, J., \& Puerta, R. (2009). Diretrizes técnicas de manejo para produção madeireira mecanizada em florestas de terra firme na Amazônia brasileira (217 p.). Belém: Embrapa Amazônia Oriental.

Saunders, D. A., Hobbs, R. J., \& Margules, C. R. (1991). Biological Consequences of ecosystem Fragmentation: A Review. Conservation Biology, 5(1), 18-32. http://dx.doi.org/10.1111/j.15231739.1991.tb00384.x.

Schwartz, G., \& Lopes, J. C. A. (2015). Loggin in the Brazilian Amazon forest: the challenges of reaching sustainable future cutting cycles. In J. A. Daniels (Ed.), Advances in environmental research (pp. 113138). Nova Publishers, New York.

Schwartz, G., Falkowski, V., \& Peña-Claros, M. (2017a). Natural regeneration of tree species in the Eastern Amazon: Short-term responses after reduced-impact logging. Forest Ecology and Management, 385, 97-103. http://dx.doi.org/10.1016/j.foreco.2016.11.036.

Schwartz, G., Lopes, J. C., Kanashiro, M., Mohren, G. M., \& Peña-Claros, M. (2014). Disturbance level determines the regeneration of commercial tree species in the eastern Amazon. Biotropica, 46(2), 148-156. http://dx.doi.org/10.1111/btp.12096.

Schwartz, G., Pereira, P. C., Siviero, M. A., Pereira, J. F., Ruschel, A. R., \& Yared, J. A. (2017b). Enrichment planting in logging gaps with Schizolobium parahyba var. amazonicum (Huber ex Ducke) Barneby: a financially profitable alternative for degraded tropical forests in the Amazon. Forest Ecology and Management, 274, 116-125. http://dx.doi.org/10.1016/j.foreco.2012.02.028.

Schwartz, G., Peña-Claros, M., Lopes, J. C. A., Morhren, G. M. J., \& Kanashiro, M. (2012). Mid-term effects of reduced-impact logging on the regeneration of seven tree commercial species in the Eastern Amazon. Forest Ecology and Management, 274, 116-125. http://dx.doi.org/10.1016/j.foreco.2012.02.028.

Sheil, D., \& May, R. M. (1996). Mortality and recruitment rate evaluations in heterogeneous tropical forests. Journal of Ecology, 84(1), 91-100.

Sheil, D., Burslem, D. F. R. P., \& Alder, D. (1995). The interpretation and misinterpretation of mortalityrate measures. Journal of Ecology, 83(2), 331-333.

Silva, J. N. M., Carvalho, J. O. P., Lopes, J. C. A., Almeida, B. F., Costa, D. H. M., de Oliveira, L. C., Vanclay, J. K., \& Skovsgaard, J. P. (1995). Growth and yield of a tropical rain forest in the Brazilian Amazon 13 years after logging. Forest Ecology and Management, 71(3), 267-274. http://dx.doi.org/10.1016/03781127(94)06106-S.

Silva, J. N. M., Carvalho, J. O. P., \& Lopes, J. C. A. (1999). Um sistema silvicultural policíclico para produção sustentada de madeira na Amazônia brasileira. In Anais do Simpósio Silvicultura na Amazônia Oriental: Contribuições do Projeto Embrapa/DFID (pp. 180-185). Belém: Embrapa-CPATU.

Silva, P. H. D., Gomide, L. R., Figueiredo, E. O., Carvalho, L. M. T. D., \& Ferraz-Filho, A. C. (2018). Optimal selective logging regime and log landing location models: a case study in the Amazon forest. Acta Amazonica, 48(1), 18-27. http://dx.doi.org/10.1590/1809-4392201603113.

Sist, P., \& Ferreira, F. N. (2007). Sustainability of reduced-impact logging in the eastern Amazon. Forest Ecology and Management, 243(2), 199-209. http://dx.doi.org/10.1016/j.foreco.2007.02.014.

Sist, P., Picard, N., \& Gourlet-Fleury, S. (2003). Sustainable cutting cycle and yields in a lowland mixed dipterocarp forest of Borneo. Annals of Forest Science, 60(8), 803-814. http://dx.doi.org/10.1051/forest:2003075.

Souza, D. V., Carvalho, J. O. P., Mendes, F. S., Melo, L. O., Silva, J. N. M., \& Jardim, F. C. S. (2014). Growth of manilkara huberi and manilkara paraensis after logging and silvicultural treatments in the municipality of Paragominas, Pará, Brazil. Floresta, 44(3), 485-496. http://dx.doi.org/10.5380/rf.v44i3.29423.

Souza, D. V., Carvalho, J. O. P., Mendes, F. S., Melo, L. O., Silva, J. N. M., \& Jardim, F. C. S. (2015). JARDIM, SILVA, F. C. Crescimento de espécies arbóreas em uma floresta natural de terra firme após a colheita de madeira e tratamentos silviculturais, no município de Paragominas, Pará, Brasil. Ciência Florestal, 25(4), 873-883. http://dx.doi.org/10.5902/1980509820585.

Taffarel, M., Gomes, J. M., Carvalho, J. O. P., Melo, L. O., \& Ferreira, J. E. R. (2014a). Efeito da silvicultura póscolheita na população de Chrysophyllum lucentifolium Cronquist (goiabão) em uma floresta de terra frme na Amazônia brasileira. Revista Árvore, 38(6), 1045-1054. http://dx.doi.org/10.1590/S010067622014000600009. 
Taffarel, M., Carvalho, J. O. P., Melo, L. O., Silva, M. G., Gomes, J. M., \& Ferreira, J. E. R. (2014b). Efeito da silvicultura pós-colheita na população de Lecythis lurida (Miers) Mori em uma floresta de terra frme na Amazônia Brasileira. Ciência Florestal, 24(4), 889-898.

van Rheenen, H. M. P. J. B. J., Boot, R. G. A., Werger, M. J. A., \& Ulloa Ulloa, M. (2004). Regeneration of timber trees in a logged tropical forest in North Bolivia. Forest Ecology and Management, 200(1-3), 3948. http://dx.doi.org/10.1016/j.foreco.2004.06.024.

Vatraz, S., Carvalho, J. O. P., Gomes, J. M., Taffarel, M., \& Ferreira, J. E. R. (2012). Efeitos de tratamentos silviculturais sobre o crescimento de Laetia procera (Poepp.) Eichler em Paragominas, PA, Brasil. Scientia Forestalis, 40(93), 95-102.

Vatraz, S., Carvalho, J. O. P., Silva, J. N. M., \& Castro, T. C. (2016). Efeito da exploração de impacto reduzido na dinâmica do crescimento de uma floresta natural. Scientia Forestalis, 44(109), 261-271. http://dx.doi.org/10.18671/scifor.v44n109.25.

Wang, X., Comita, L. S., Hao, Z., Davies, S. J., Ye, J., Lin, F., \& Yuan, Z. (2012). Local-scale drivers of tree survival in a temperate forest. PLoS One, 7(2), e29469. http://dx.doi.org/10.1371/journal.pone.0029469. PMid:22347996.

Wu, H., Franklin, S. B., Liu, J., \& Lu, Z. (2017). Relative importance of density dependence and topography on tree mortality in a subtropical mountain forest. Forest Ecology and Management, 384, 169-179. http://dx.doi.org/10.1016/j.foreco.2016.10.049.

Contribuição dos Autores: LFSD: conceitualização, redação científica; curadoria de dados, análise formal. 